\title{
An exploration of the Rs of radiobiology in prostate cancer.
}

ROBERTS, C. and PATERSON, C.

2020 
Title: An exploration of the Rs of Radiobiology in Prostate Cancer

Authors: Roberts, C (BSc), Paterson, C (PhD, MSc, BA, PG Cert LTA, FHEA, RAN)

\section{Corresponding Author:}

Cara Roberts

School of Nursing, Midwifery and Public Health

Faculty of Health,

University of Canberra

Australia

Email: cara.roberts@canberra.edu.au 


\section{Abstract}

Objectives: To explore the Four Rs of Radiobiology (Repair, Reoxygenation, Reassortment and Repopulation) as a means to understand the effects of ionising radiation on biological tissue and subsequently as the basis for conventional fractionated treatment schedules. These radiobiological principles will form a rationale for combined regimens in prostate cancer (PCa) treatment involving Androgen Deprivation Therapy (ADT) and Radiation Therapy (RT) and the associated toxicities of this approach will be discussed.

Data Sources: Electronic databases including CINAHL, MEDLINE, Scopus, professional websites, books and grey literature were searched using Google scholar.

Conclusion: It is important for nurses to understand the Four Rs of Radiobiology to grasp the effects of ionising radiation on biological tissue as the basis for conventional fractionated treatment schedules in PCa. Men can experience a sequalae of physical and psychological side-effects of treatment which can negatively impact quality of life.

Implications for Nursing Practice: Men can experience a range of unmet supportive care needs particularly related to informational, sexual and psychological needs. For men affected by PCa opting for RT (+/-) ADT nurses should ask targeted questions based on the Common Terminology Criteria for Adverse Events (CTCAE) related to urinary and bowel function, potency and fatigue and sexual health. We also recommend the use of holistic needs assessments to tailor self-management care plans. Evidence-based self-management advice should be provided in response to each man's unique needs.

Keywords: Radiobiology; 4Rs, Prostate Cancer; Androgen Deprivation Therapy; Toxicities; Specialist Nursing 


\section{Introduction}

The biological effect that ionising radiation has on both normal and tumour tissue can be understood through the exploration of four radiobiological principles $\left(4 R^{\prime} s\right)$ : Repair of sublethal damage, Reoxygenation, Reassortment and Repopulation. The Radiosensitivity of specific cells is also pertinent to the process (this is sometimes referred to as the fifth ' $R$ ') however, it is inextricably linked to Repair [1]. These principles are used to justify dose fractionation in radiation treatment [2]. When a treatment dose is divided into fractions and enough time is provided between doses, normal tissues have the ability to recover through repair and repopulation of cells into the tissues, and the tumour itself is adversely affected by the reoxygenation and reassortment of cells [3].

Understanding this interaction between ionising radiation and tumour tissues can allow the microenvironment, in more radioresistant cells, to be manipulated and sensitised by the introduction of adjuvant therapies $[4,5]$. The combined use of ADT with RT in the treatment of PCa, is an example of this symbiotic relationship, noting that an improvement in overall survival is observed with traditional treatment modalities, compared with RT alone [6-9]. However, given the myriad of potential side effects that accompany ADT, alongside the technological advances in contemporary RT that permit larger doses to the tumour bed with greater precision, clinical trials are underway to assess the continued efficacy of a multimodal approach at higher RT doses $[10,11]$. Although, these trials are yet to divulge conclusive findings and therefore (neo)adjuvant interventions remain standard practice for particular biochemical disease manifestations [12]. Duration and timing of ADT are also variables that have warranted investigation, with the intent to strike an optimal balance between oncological benefit and toxicity related quality of life (QoL) considerations [4].

Therefore, this article will provide an overview of the concept of the $4 R^{\prime} s$ of radiobiology and contextualise them in relation to combination $A D T / R T$ and the resulting toxicity risks in PCa treatment approaches. 


\section{Radiobiological Principles}

\section{Repair of Sublethal Damage}

Ionising radiation can cause a cascade of events within a cell that will ultimately lead to a transient or permanent alteration [13]. The most important target within that cell is the DNA, as it contains the genetic information required to maintain cell survival and function. Damage to the DNA may lead to either cell malfunction or cell death and this can occur when radiation acts directly on the DNA or indirectly by acting elsewhere in the cell, particularly on water molecules in the presence of oxygen. This induces the formation of free radicals, which are highly reactive and will combine with other atoms to cause chemical change and damage within a cell [14]. Damage to the DNA can either result in a single strand break, which is easily rectified or a double strand brand break, which results in cell death or permanent alterations (when the chromosomes re-join incorrectly) if the repair processes are not sufficient [3]. Cell kill from ionising radiation occurs through the generation of unrepairable lesions involving DNA double strand breaks [15]. The majority of DNA damage is sublethal and has the capacity for repair within hours unless additional sublethal damage occurs [3]. Sublethal damage repair conceptualises the idea that cell killing is reduced if a dose of radiation is delivered in two or more fractions with a given time interval [14]. Repair of sublethal damage is nutrient and oxygen dependent and because the majority of tumour cells are thought to have a hypoxic component, they are considered less effective at carrying out the repair process than normal tissues [16]. The rate of repair and the inherent cellular radiosensitivity will have significant bearing on the response to radiation and consequently the overall ability to eradicate tumour cells, thereby reducing the incidence of recurrence and relapse [17]. This is clinically significant as the tissue's radiosensitivity and capacity for repair inform the prescribed dose fractionation and interfraction interval to allow normal tissues to repair [1] while preventing the possibility of chromosomal aberrations, which could be detrimental in years to come [3]. 


\section{Reoxygenation}

The efficacy of radiation can be linked to the availability of oxygen within the target tissue. Blood supply to a tissue is a major determinant in the amount of available oxygen. Normal tissues have an adequate supply to all areas through a network of capillaries however, tumours tend to outgrow their blood supply leading to areas of hypoxia [14]. The hypoxic regions can be found throughout the tumour and can drastically affect the cytotoxicity of radiation and therefore impede its success [2]. The oxygen saturation of cells is dynamic, and tumours can be both acutely and chronically hypoxic [18]. Acute hypoxia occurs when there is an intermittent and temporary closure of the supplying blood vessels and chronic hypoxia occurs when cells are not close enough to the blood supply to allow diffusion of oxygen to take place [15]. Hypoxic cells gain access to oxygen through a process of reoxygenation. Providing sufficient time is allocated between radiation doses a proportion of cells will have time to reoxygenate and become more sensitive to the next treatment [16]. The biological and radiation response of the cells is directly affected by the extent of the hypoxic conditions and the amount of time spent in the hypoxic state. Cells that are irradiated shortly following the reoxygenation process have a higher radiosensitivity than those irradiated after being in hypoxic conditions for up to 24 hours [15]. Reoxygenation of hypoxic cells is possible and particularly effective when dose fractionation is employed. This is due to the likelihood of the first dose fraction killing a large proportion of the well oxygenated and radiosensitive cells located near the tumours blood supply [16]. Following irradiation, a large fraction of cells become hypoxic however, this is short lived as the tumour returns to its original proportions of oxygenated and hypoxic cells [19]. As the dead cells are broken down and removed, the tumour shrinks and undergoes revascularisation and restructuring, so that those surviving hypoxic cells now have access to a blood supply and are able to reoxygenate. These newly reoxygenated cells are now more sensitive to the next dose fraction of radiation [3] , see Figure 1. 


\section{Reassortment}

Reassortment or redistribution recognises that cells exhibit differential radiation sensitivity during different phases of the cell cycle [15]. The cell cycle can be divided into four separate and distinctive phases, see Figure 2:

- $\mathrm{G} 1$ - The cells are preparing for replication.

- $\mathrm{S}$ - Is the stage where the DNA is replicated or synthesised

- $\mathrm{G} 2$ - The cells are preparing for division

- Mitosis (M) - The chromosomes condense and divide to produce identical daughter cells [2]

If a cell moves out of the active cell cycle and rests (does not divide) it is considered to be in the G0 phase. Cells can also leave G0 and move back into the active cycle to increase cells numbers. Prior to irradiation a population of cells will tend to show an asynchronous distribution, that is, the cells will be dispersed throughout all phases of the cell cycle [16]. Those cells that are located in the Mitosis and G2 phases will be more sensitive to radiation induced killing, whereas those cells moving through the $S$ phase (particularly the late $S$ phase) will be the most radioresistant [20]. Following irradiation, cells that were once randomly distributed will synchronise, as those that were located in the sensitive stages have been killed off leaving only those in the more resistant phase. Clinically, an ideal situation exists when radiation treatment can be timed to target tumour cells as they move into the sensitive phase of the cell cycle, preserving normal cells that have moved into the resistant phase [16]. Redistribution into the sensitive phases of the cycle is dependent on the ability of the cells to proliferate. The normal non-proliferating tissues such as the spinal cord and connective tissue may not be affected while those tissues experiencing rapid proliferation, such as tumours can be more sensitised to redistribution [21]. Variation in cell sensitivity is an important consideration for the delivery of radiation treatment. Delivery of ionising radiation in fractionated doses improves the probability that tumour cells will be in the sensitive phase of the cell cycle at some point during the treatment regime resulting in increased tumour cell kill [3]. 


\section{Repopulation}

As previously established, not all cells are active within the cell cycle. Those that are 'resting' (those located in G0) can enter the cell cycle at any stage to replace the cells that have incurred radiation damage and been destroyed [14]. The clonogens (surviving cells) in the surrounding tissue or the tumour itself commence cell division and partially or completely repopulate the area [16]. Repopulation can occur through either cell proliferation or cell immigration. Cell proliferation occurs in tissues with a rapid rate of cell production and those that can meet demand by speeding up cell production (such as skin). Cell migration involves stem cells moving into the necessary location and differentiating to perform the desired functions [21]. The microenvironments role in driving repopulation is dependent on an individual's immune status, tumour type and planned radiation schedule [22]. It is highly beneficial for normal tissues to repopulate, as this can minimise the accumulative long-term effect that radiation can have on tissues with low proliferation rates. However, repopulation of tumour cells is highly disadvantageous to the radiation therapy treatment process [16]. As radiation is a cytotoxic treatment agent it can actually promote cell division to occur at a higher rate, this is termed accelerated repopulation [3]. Accelerated repopulation is detrimental to the cure rate of malignant cells unless the treatment doses match the rate of cell production [14]. Given inter-tumour variability can be substantial, a balance of time is essential in Radiation Therapy to counteract the effects of repopulation within a tumour [19]. If the treatment period exceeds a certain amount of time, approximately 28 days (which is when the cells will commence repopulation) then a daily compensational dose increment is necessary, otherwise the overall effectiveness of treatment will be reduced [3]. Fractionated doses are a means of sparing normal tissues within the treatment field and accelerated treatment regimens can be developed to deliver the total dose within a shorter time frame to compensate for repopulation [14]. 


\section{Combined Treatments in Prostate Cancer}

Biological Basis for Combined Treatment

Androgens are a group of male sex hormones that are synthesised in the adrenal glands and interstitial cells of the testes. They are responsible for sexual and reproductive function in men, with gonadal testosterone comprising the main source of circulating androgens [23, 24]. Both normal and abnormal (cancerous) cells in the prostate gland rely on testosterone to grow [25] and because PCa is susceptible to androgens, rendering it a hormone-sensitive disease, it has been identified to significantly benefit from ADT, which can be implemented at various points throughout the PCa treatment trajectory [26]. Typically, PCa cells are considered radioresistant, as testosterone activates androgen receptors (AR) and in turn stimulates the DNA repair pathways that would have otherwise been damaged when interacting with ionising radiation. It is the AR signalling that encourages the continued growth and survival of the tumour cells $[4,24,27]$. The tumours dependence on AR activity can be manipulated when hormone therapy is used as an adjunct to the radiation regimen. ADT can alter the tumour microenvironment by inhibiting cell repopulation and proliferation and deactivating the DNA repair machinery leaving the cells more sensitive to radiation [5]. It is also postulated that ADT can improve PCa cell re-oxygenation, normalise the vasculature and consequently enhance tissue perfusion. All of which increase the likelihood of radiation induced cell kill, without compromising the integrity of the normal surrounding tissues $[4,5]$.

\section{Supporting Evidence for Combined Treatment}

Evidence underscores that using ADT in combination with RT can improve local tumour control and mitigate the risk of distant metastasis, thereby impacting on long-term disease free survival for those patients with locally advanced and high risk disease [4, 28], see Table 1 and Table 2 for diagnostic classifications. The European Organisation for Research and Treatment of Cancer (EORTC) conducted a phase III trial comprising 415 patients, with high risk localised or locally advanced disease, who were randomised to RT (70Gy) with or without long term (3 years) adjuvant ADT. The overall survival 
at 5 years was $78 \%$ for combined treatment and $62 \%$ for RT alone. EORTC also established that those surviving at 5 years had a disease free rate of $74 \%$ for the combined treatment compared with $40 \%$ for RT alone $[29,30]$. The 10 -year results of this trial maintained superior outcomes for combined treatment across multiple domains, with $58.1 \%$ overall survival recorded compared with $39.8 \%$ in RT alone. Locoregional failure rate was significantly reduced for the combined approach compared with RT alone, reporting $6.0 \%$ and $23.5 \%$ respectively. The combined treatment group demonstrated $51 \%$ distant metastasis free survival versus $30.2 \%$ for RT and finally there was a statistically significant reduction in prostate cancer mortality at 10 years with $10.3 \%$ mortality rate for combined group as opposed to $30.4 \%$ for the single treatment RT group [31].

These findings were confirmed by Mason et al who conducted a large intergroup study to determine whether overall survival would benefit from the addition of RT to ADT. 1,205 men were randomly assigned to lifelong ADT alone or to a combination of ADT and RT (64-69Gy). With a median follow up of 8 years, an improvement was documented in both prostate specific and overall survival outcomes for those partaking in combined therapy. ADT and RT together resulted in a significant reduction in prostate cancer related death $(\mathrm{P}<0.001)$ and the overall risk of death had reduced by $30 \%$. The 10 year overall survival rate was $55 \%$ for those undergoing ADT and RT compared with $49 \%$ for those receiving ADT alone [32]. Amit et al [7] posed the question as to whether the addition of ADT was still beneficial in men with intermediate risk prostate cancer receiving a higher dose of RT (78-82Gy). The results found a beneficial role for the addition of short-term ADT with this particular group however, biochemical relapse free survival at 6 year follow up favoured men $\leq 70$ years $(82.1 \%$ for RT alone and $94 \%$ for combined therapy). Interestingly those patients $>70$ years revealed no significant difference between treatment groups. 


\section{Duration of $A D T$}

The continued advantage of combining ADT with modern (higher) RT doses is an area that has sparked considerable debate. Much of the evidence available uses doses far below current standards however, a study involving 168 patients with high risk PCa receiving ADT, with the addition of dose escalated RT (80Gy), achieved 79\% biochemical progression free rate at 5 year follow up [32]. As more contemporary results emerge, it has become clear that there are many variables involved in changing the landscape of current practice and a consistent thread in the literature is a lack of consensus regarding the optimal duration of $\operatorname{ADT}[6,33]$. Although advances in RT treatment planning and delivery may not preclude the need for ADT with intermediate or high risk patients, it may provide the option to reduce the duration of hormonal therapy, minimising the prevalence of life altering toxicities and allowing earlier testosterone recovery [4]. Bolla et al [34] concluded that implementing 6 months of ADT with a RT dose up to 78Gy would be an acceptable compromise between disease management and QoL. They reported a statistically significant difference in the 5year biochemical disease-free rate between the combined treatment arm (82.6\%) and RT alone (69.8\%). Zapetero et al [11] undertook a phase III trial, which aimed to bridge the gap between duration of ADT and contemporary RT treatment modalities. The patients were assigned to either short duration ADT, receiving 2 months neoadjuvant therapy and another 2 months combined with RT (4 months total) or long-term ADT which continued hormone suppression for a total of 24 months. Both groups received an isocentre dose of 78Gy to the prostate. The results indicate a clear benefit in favour of long-term ADT in combination with high dose RT for those with high risk pathology. Disease free survival at 5 years was $90 \%$ for those on long term ADT compared to $81 \%$ of those in the short-term ADT group.

Noteworthy, is the risk of non-compliance for those studies involving long term ADT. The RTOG 8531 trial revealed that $25 \%$ and $68 \%$ of patients prescribed lifelong ADT voluntarily ceased treatment at 2 years and 5 years respectively [9]. A study conducted by Nabid et al [35] noted a compliance rate of 
$53 \%$ for long term ADT (36 months), in contrast $88 \%$ of patients were found to comply with intermediate term ADT (18 months). There was also minimal difference in overall survival at a 9.4year follow-up for those receiving a shorter duration of ADT. A systematic review identified that the evidence supports 24 months of adjuvant ADT with RT however, the findings do not necessitate extending treatment beyond that time frame for high risk patients, with consideration given to preexisting comorbidities when deciding optimal duration [6].

\section{Toxicities}

$A D T$

While there are many benefits of using ADT in the treatment of PCa, there is a constellation of welldocumented adverse effects than can have a drastic and negative impact on quality of life (QoL) and potentially exacerbate pre-existing co-morbidities [7]. The severity of toxicity side-effects of ADT include: fatigue, hot flushes, sexual dysfunction (loss of libido and erectile dysfunction), cognitive decline, altered body composition (obesity and sarcopenia), atherosclerosis, osteoporosis with increased risk of fracture, gynecomastia and metabolic syndrome (elevated triglycerides, increased waist circumference and insulin resistance) which may eventuate in new onset diabetes mellitus [27, $34,36]$.

More striking are the implications that androgen suppression may be associated with an increased risk of cardiovascular (CV) related events and CV mortality, although this remains somewhat controversial. In the earliest study to suggest a link between CV risk and ADT, Keating et al [37] undertook a SEER-Medicare review of over 73,000 men with locoregional PCa receiving a gonadotropin-releasing hormone $(\mathrm{GnRH})$ agonist and found an increased risk of $16 \%$ for coronary heart disease, $11 \%$ for myocardial infarction (MI) and $16 \%$ for sudden cardiac death. Following a pooled analysis of men in three randomised trials with varying durations of ADT, D'Amico et al [38] noted that men $>65$ years receiving 6 months of ADT had shorter times to fatal MI however, this 
may be attributed to pre-existing comorbidities. In a prospective cohort study, Haque et al [39] found that men with localised PCa using ADT were at greater risk of certain CV disease outcomes, such as heart failure, whereas arrhythmias and conduction disorders were only prevalent in those with preexisting CV conditions. The majority of evidence reporting a plausible link derives from large observational studies however, contrary to D'Amico's conclusions, when other randomised trials were reanalysed to assess the risk of $A D T$ related $C V$ events between those men receiving or not receiving $A D T$, there was no direct correlation established [40]. There is still uncertainty as to whether the susceptibility is due to the older age group in which PCa is most prominent and the likelihood that pre-existing conditions become more pronounced with ADT related metabolic abnormalities [41]. Ongoing research specifically designed to capture the effects of different ADT drugs on CV risk may provide further clarity in this controversial area [41, 42].

ADT has the propensity to accelerate the loss of bone mineral density (BMD), which has significant implications for osteoporosis and is a surrogate marker for fracture risk within the ageing PCa population [26]. There tends to be a higher rate of bone loss earlier in the treatment trajectory, but this steadily decreases over time. The areas incurring the greatest degree of bone loss include lumbar vertebrae (-3.6\%), femoral neck (-3.11\%) and total hip area (-1.59\%) [43]. Observational studies have yielded fairly consistent results regarding fracture risk with a recent retrospective study capturing a $39 \%$ increase in overall risk, which continued to rise with ADT duration [44]. Fractures are an important consideration for men with PCa on ADT as they can be associated with reduced QoL and are also an independent predictor of decreased overall survival [26, 29].

$R T$

Patients on ADT who are also undergoing RT often have to contend with additional acute or late toxicities, particularly those that arise from the dose-limiting organs at risk (OAR) falling within the radiation field, including the bilateral femoral heads, the bladder and rectum [45]. Although 
technological advances in RT techniques are protective factors for these vulnerable structures, there is still the occurrence of daily treatment uncertainties such as set up errors, variation in the size and shape of the prostate, changes in bladder and rectum volumes and inter/intrafraction motion of the prostatic bed $[46,47]$.

There is a dearth of literature pertaining to RT induced hip-related complications. While this toxicity is less common, it is an important consideration with newer treatment plans employing higher radiation doses, especially for those using ADT who are already at an increased risk of osteoporotic changes [48]. Elliot et al [49] reported an increased risk of $76 \%$ for hip fractures associated with RT and a further increase for those on combined treatment, without increasing the risk of fragility fractures in bones outside of the radiation area (distal forearm). However, Zelefksy et al [48] suggests the risk is negligible with appropriate planning and application of dose constraints to the femoral heads, therefore it is only those with pre-existing degenerative joint disorders or prolonged ADT exposure that may be at increased risk.

The most investigated radiation dose-volume relationships focus on genitourinary (GU) and gastrointestinal (GI) toxicities, noting that the risk factors vary for each individual patient based on their unique clinical and personal profiles [50]. When comparing combined treatment with ADT as a monotherapy, the evidence consistently reflects that both GU and GI side effects are transient in nature with little clinically or statistically significant difference in symptom scores at long term follow-up [51]. Warde et al [52] noted that the adverse effects in the combined treatment group were clinically modest and short-lived, with Grade 1 and Grade 2 Gl toxicities, see Table 3, (manageable diarrhoea and rectal bleeding) evident at 6 months but noted recovery by 36 months. GU scores were already elevated at baseline due to disease related symptoms. Mason et al [32] reiterated that toxicities were more pronounced for combined treatment initially with urinary frequency recorded at $7 \%$ for ADT/RT compared to $4 \%$ for ADT alone. Once again, severe Gl events 
were negligible at a 24 month follow up. Sargos et al [53] reported that $\geq$ Grade 2 GU and GI toxicities were more frequent in the combined arm compared with ADT alone (GI $=17 \%$ vs $1 \%$ and $\mathrm{GU}=12 \%$ vs $1 \%$ ) however, after 6 months these gradually decreased throughout the follow-up period. With radiation centres implementing strict bladder and bowel preparation protocols, the advances in radiation technology and inclusion of image guided RT, the radiation dose to the prostate can be delivered with a high level of conformality, in turn reducing the dose received by the OAR and surrounding tissues, while still achieving superior biochemical control [54, 55].

\section{Nursing Implications}

It is important for nurses to understand the Four Rs of Radiobiology (Repair, Reoxygenation, Reassortment and Repopulation) to understand the effects of ionising radiation on biological tissue and subsequently as the basis for conventional fractionated treatment schedules. An important aspect of nursing of men receiving RT (+/- ADT) is the provision of care, support and selfmanagement advice [56]. Men can experience a range of unmet supportive care needs particularly related to informational, sexual and psychological needs [57]. For men affected by PCa opting for RT nurses should ask targeted questions based on the Common Terminology Criteria for Adverse Events (CTCAE) related to urinary and bowel function, potency and fatigue and sexual health [58]. We also recommend the routine use of holistic needs assessments to tailor self-management care plans [59]. Evidence-based self-management advice should be provided in response to each man's unique needs [60]. Nurses providing care to men requires expert technical knowledge and advanced communication skills. Care provision must reflect evidence-based clinical guidelines and care provision must be safely structured within the multidisciplinary team.

\section{Conclusion}

It is important for nurses to understand the Four Rs of Radiobiology to grasp the effects of ionising radiation on biological tissue as the basis for conventional fractionated treatment schedules in PCa. 
Men can experience a sequalae of physical and psychological side-effects of treatment which can negatively impact quality of life. Nurses can provide expert technical knowledge with advanced communication skills to ensure tailored, person-centred evidence-based self-management care plans. 


\section{References}

1. Zeman, E.M., The history and radiobiology of hypofractionation, in Hypofractionated and Stereotatic Radiation Therapy: A Practical Guide O. Kaider-Person, \& Chen, R., Editor. 2018, Springer International Publishing AG: Cham, Switzerland.

2. McMillan, T.J., Principles of radiobiology, in Walter and Miller's Textbook of Radiotherapy: Radiation Physics, Therapy and Oncology, C.K. Bomford, \& Kunkler, I. H., Editor. 2003, Churchill Livingstone: London, UK.

3. Hall, E.J., \& Giaccia, A.J., Radiobiology for the Radiologist. 8 ed. 2018, Philadelphia, USA: Walters Kluwer.

4. Kauffmann, G., \& Liauw, S. L., The use of hormonal therapy to augment radiation therapy in prostate Cancer: an update. Current urology reports, 2017. 18(7): p. 50.

5. Keyes, M., Merrick, G., Frank, S. J., Grimm, P., \& Zelefsky, M. J., American Brachytherapy Society Task Group Report: Use of androgen deprivation therapy with prostate brachytherapy -A systematic literature review. Brachytherapy, 2017. 16(2): p. 245-265.

6. Moris, L., Cumberbatch, M. G., Van den Broeck, T., Gandaglia, G., Fossati, N., Kelly, B., Pal, R., Briers, E., Cornford, P., \& De Santis, M. Fanti, S., Gillessen, S., Grummet, J. P., Henry, A. M., Lam, T. B.L., Lardas, M., Liew, M., Mason, M. D., Omar, M. I., Rouviere, O., Schoots, I. G., Tilka, D., van den Bergh, R. C.N., van Der Kwast, T. H., van Der Poel, H. G., Willemse, P-P. M., Yuan, C. Y., Konety, B., Dorff, T., Jain, S., Mottet, N., \& Wiegel, T., Benefits and Risks of Primary Treatments for High-risk Localized and Locally Advanced Prostate Cancer: An International Multidisciplinary Systematic Review. European Urology, 2020.

7. Amit, U., Lawrence, Y. R., Weiss, I., \& Symon, Z., Radiotherapy with or without androgen deprivation therapy in intermediate risk prostate cancer? Radiation Oncology, 2019. 14(1): p. 99.

8. Amini, A., Rusthoven, C. G., Jones, B. L., Armstrong, H., Raben, D., \& Kavanagh, B. D. Survival outcomes of radiotherapy with or without androgen-deprivation therapy for patients with 
intermediate-risk prostate cancer using the National Cancer Data Base. in Urologic Oncology: Seminars and Original Investigations. 2016. Elsevier.

9. Mohiuddin, J.J., Baker, B. R., \& Chen, R. C., Radiotherapy for high-risk prostate cancer. Nature Reviews Urology, 2015. 12(3): p. 145.

10. Pisansky, T.M., Hunt, D., Gomella, L. G., Amin, M. B., Balogh, A. G., Chinn, D. M., Seider, M. J., Duclos, M., Rosenthal, S. A., Bauman, G. S., Gore, E. M., Rotman, M. Z., Lukka, H. R., Shipley, W. U., Dignam, J. J., \& Sandler, H. M., Duration of androgen suppression before radiotherapy for localized prostate cancer: radiation therapy oncology group randomized clinical trial 9910. Journal of Clinical Oncology, 2015. 33(4): p. 332.

11. Zapatero, A., Guerrero, A., Maldonado, X., Alvarez, A., San Segundo, C. G., Rodríguez, M. A. C., M, V., Olive, A. P., Casas, F., Boladeras, A., de Vidales, C. M., de la Torre, M. L. V., Villa, S., de la Haza, A. P., \& Calvo, F. A., High-dose radiotherapy with short-term or long-term androgen deprivation in localised prostate cancer (DART01/05 GICOR): a randomised, controlled, phase 3 trial. The Lancet Oncology, 2015. 16(3): p. 320-327.

12. Vargas, C.E., Alam, N. B., Terk, M., Niska, J. R., Cesareti, J., Swartz, D., Vashi, A., Kasraeian, A., West, C. S., \& Blasser, M., Initial results of a randomized phase III trial of high dose image guided radiation with or without androgen deprivation therapy for intermediate-risk prostate cancer. Cancer treatment and research communications, 2019. 19: p. 100119.

13. Kumar, V., Abbas. A.K., \& Aster, J.C., Environmental and nutritional diseases, in Robbins Basic Pathology. 2018, Elsevier: Philadelphia, USA.

14. Adamson, D., The radiobiological basis of radiation side effects, in Supportive Care in Radiotherapy S. Faithful, \& Wells, M., Editor. 2003, Elsevier Limited: London, UK.

15. Pajonk, F., Vlashi, E., \& McBride, W.H., Radiation resistance of cancer stem cells: the $4 R^{\prime}$ 's of radiobiology revisited. Stem cells, 2010. 28(4): p. 639-648.

16. Passmore, G.C., Overview of radiobiology, in Principles and Practice of Radiation Therapy, C.M. Washington, \& Lever, D., Editor. 2016, Mosby Elsevier: Missouri, USA. 
17. Pavlopoulou, A., et al., Molecular determinants of radiosensitivity in normal and tumor tissue: A bioinformatic approach. Cancer letters, 2017. 403: p. 37-47.

18. Herskind, C., et al., Biology of high single doses of IORT: RBE, $5 R^{\prime}$ 's, and other biological aspects. Radiation Oncology, 2017. 12(1): p. 24.

19. Brenner, D.J., \& Carlson, D.J., Radiobiological principles underlying stereotatic radiation therapy, in Principles and Practice of Stereotatic Radiosurgery, L.S. Chin, \& Regine, W.F. , Editor. 2015, Springer Science Business Media: New York, USA.

20. Boustani, J., et al., The 6 th $R$ of radiobiology: reactivation of anti-tumor immune response. Cancers, 2019. 11(6): p. 860.

21. Trott, K.-R., Experimental results and clinical implications of the four R's in fractionated radiotherapy. Radiation and Environmental Biophysics, 1982. 20(3): p. 159-170.

22. Good, J.S., \& Harrington, K.J., The hallmarks of cancer and the radiation oncologist: updating the 5Rs of radiobiology. Clinical oncology, 2013. 25(10): p. 569-577.

23. F.H., M., Findamentals of Anatomy and Physiology 5th ed. 2001, NJ, USA: Prentice-Hall Inc.

24. Sharifi, N., Gulley, J. L., \& Dahut, W. L., An update on androgen deprivation therapy for prostate cancer. Endocrine-related cancer, 2010. 17(4): p. R305-R315.

25. Epstein, J.I., \& Lotan, T. L., Male genital system and lower urinary tract, in Robbins Basic Pathology, V. Kumar, Abbas. A. K., \& Aster, J.C., Editor. 2018, Elsevier Philadelphia, USA.

26. Magee, D.E., \& Singal, R. K., Androgen deprivation therapy: indications, methods of utilization, side effects and their management. Can J Urol, 2020. 27(Suppl 1): p. 11-16.

27. Grossmann, M., Cheung, A. S., \& Zajac, J. D., Androgens and prostate cancer; pathogenesis and deprivation therapy. Best Practice \& Research Clinical Endocrinology \& Metabolism, 2013. 27(4): p. 603-616.

28. Mottet N., B.J., Briers E., Bolla M., Bourke L., Cornford P., De Santis M., Henry A., Joniau S., Lam T., Mason M.D., Van den Poel H., Van den Kwast T.H., Rouvière O., Wiegel T. EAU- 
ESTRO-SIOG Guidelines on Prostate Cancer. 2020 April 16, 2020]; Available from:

https://uroweb.org/guideline/prostate-cancer/\#6.

29. Schulman, C.C., Irani, J., Morote, J., Schalken, J. A., Montorsi, F., Chlosta, P. L., \& Heidenreich, A., Androgen-deprivation therapy in prostate cancer: a European expert panel review. European Urology Supplements, 2010. 9(7): p. 675-691.

30. Sharifi, N., Gulley, J. L., \& Dahut, W. L., Androgen deprivation therapy for prostate cancer. Jama, 2005. 294(2): p. 238-244.

31. Bolla, M., Van Tienhoven, G., Warde, P., Dubois, J. B., Mirimanoff, R-O., Storme, G., Bernier, J., Kuten, A., Sternberg, C., \& Billiet, I. , External irradiation with or without long-term androgen suppression for prostate cancer with high metastatic risk: 10-year results of an EORTC randomised study. The lancet oncology, 2010. 11(11): p. 1066-1073.

32. Mason, M.D., Parulekar, W. R., Sydes, M. R., Brundage, M., Kirkbride, P., Gospodarowicz, M., Cowan, R., Kostashuk, E. C., Anderson, J., Swanson, G., Parmar, M. K.., Hayter, C., Jovic, G., Hiltz, A., Hetherington, J., Sathya, J., Barber, J. B.p., McKenzie, M., El-Sharkawi, S., Souhami, L., Hardman, J., Bingshu, E. C., \& Warde, P., Final report of the intergroup randomized study of combined androgen-deprivation therapy plus radiotherapy versus androgen-deprivation therapy alone in locally advanced prostate cancer. Journal of Clinical Oncology, 2015. 33(19): p. 2143.

33. Payne, H., \& Mason, M., Androgen deprivation therapy as adjuvant/neoadjuvant to radiotherapy for high-risk localised and locally advanced prostate cancer: recent developments. British journal of cancer, 2011. 105(11): p. 1628-1634.

34. Bolla, M., Maingon, P., Carrie, C., Villa, S., Kitsios, P., Poortmans, P. M.P., Sundar, S., van der Steen-Banasik, E. M., Armstrong, J., Bosset, J-F., Herrera, F. G., Pieters, B., Slot, A., Bahl, A., Ben-Yosej, R., Boehmer, D., Scrase, C., Renard, L., Shash, E., Coens, C., van den Bergh, A. C.M., \& Collette, L., Short androgen suppression and radiation dose escalation for 
intermediate-and high-risk localized prostate cancer: results of EORTC trial 22991. Journal of Clinical Oncology, 2016. 34(15): p. 1748-1756.

35. Nabid, A., Carrier, N., Martin, A-G., Bahary, J-P., Lemaire, C., Vass, S., Bahoric, B., Archambault, R., Vincent, F., \& Bettahar, R., Duration of androgen deprivation therapy in high-risk prostate cancer: a randomized phase III trial. European urology, 2018. 74(4): p. 432441.

36. Isbarn, H., Boccon-Gibod, L., Carroll, P. R., Montorsi, F., Schulman, C., Smith, M. R., Sternberg, C. N., \& Studer, U. E., Androgen deprivation therapy for the treatment of prostate cancer: consider both benefits and risks. European urology, 2009. 55(1): p. 62-75.

37. Keating, N.L., O'Malley, A. J., \& Smith, M. R., Diabetes and cardiovascular disease during androgen deprivation therapy for prostate cancer. Journal of Clinical Oncology, 2006. 24(27): p. $4448-4456$.

38. D'Amico, A.V., Chen, M-H., Renshaw, A. A., Loffredo, M., \& Kantoff, P. W., Androgen suppression and radiation vs radiation alone for prostate cancer: a randomized trial. Jama, 2008. 299(3): p. 289-295.

39. Haque, R., UlcickasYood, M., Xu, X., Cassidy-Bushrow, A. E., Tsai, H-T., Keating, N. L., Van Den Eeden, S. K., \& Potosky, A. L., Cardiovascular disease risk and androgen deprivation therapy in patients with localised prostate cancer: a prospective cohort study. British journal of cancer, 2017. 117(8): p. 1233-1240.

40. Nguyen, P.L., Alibhai, S. M.H., Basaria, S., D’Amico, A. V., Kantoff, P. W., Keating, N. L., Penson, D. F., Rosario, D. J., Tombal, B., \& Smith, M. R., Adverse effects of androgen deprivation therapy and strategies to mitigate them. European urology, 2015. 67(5): p. 825836.

41. Melloni, C., \& Roe, M. T. Androgen deprivation therapy and cardiovascular disease. in Urologic Oncology: Seminars and Original Investigations. 2020. Elsevier. 
42. Zareba, P., Duivenvoorden, W., Leong, D. P., \& Pinthus, J. H. , Androgen deprivation therapy and cardiovascular disease: what is the linking mechanism? Therapeutic advances in urology, 2016. 8(2): p. 118-129.

43. Edmunds, K., Tuffaha, H., Galvão, D. A., Scuffham, P., \& Newton, R. U., Incidence of the adverse effects of androgen deprivation therapy for prostate cancer: a systematic literature review. Supportive Care in Cancer, 2020: p. 1-15.

44. Nguyen, C., Lairson, D. R., Swartz, M. D., \& Du, X. L., Risks of major long-term side effects associated with androgen-deprivation therapy in men with prostate cancer. Pharmacotherapy: The Journal of Human Pharmacology and Drug Therapy, 2018. 38(10): p. 999-1009.

45. Pereira, A.A.C., Grubert, D. H., Ferreira, G. G., Ferreira, J. O. H. R., Aleixo, D. L., \& Moreschi, A. R. C., Late side effects after radiation therapy in patients with prostate cancer: $2 D$ vs $3 D$ vs IMRT. Clinical Oncology and Research, 2020. 3(1): p. 2-8.

46. Fuchs, F., Habl, G., Devečka, M., Kampfer, S., Combs, S. E., \& Kessel, K. A., Interfraction variation and dosimetric changes during image-guided radiation therapy in prostate cancer patients. Radiation oncology journal, 2019. 37(2): p. 127.

47. Chen, Z., Yang, Z., Wang, J., \& Hu, W., Dosimetric impact of different bladder and rectum filling during prostate cancer radiotherapy. Radiation Oncology, 2016. 11(1): p. 103.

48. Zelefsky, M.J., Kollmeier, M. A., Gorshein, E., Pei, X., Torres, M., McBride, S., Happersett, L., Gil'ad, N. C., \& Yamada, Y., Hip-related toxicity after prostate radiotherapy: Treatment related or coincidental? Radiotherapy and Oncology, 2016. 121(1): p. 109-112.

49. Elliott, S.P., Jarosek, S. L., Alanee, S. R., Konety, B. R., Dusenbery, K. E., \& Virnig, B. A., Three-dimensional external beam radiotherapy for prostate cancer increases the risk of hip fracture. Cancer, 2011. 117(19): p. 4557-4565.

50. Landoni, V., Fiorino, C., Cozzarini, C., Sanguineti, G., Valdagni, R., \& Rancati, T., Predicting toxicity in radiotherapy for prostate cancer. Physica Medica, 2016. 32(3): p. 521-532. 
51. Brundage, M., Sydes, M. R., Parulekar, W. R, Warde, P., Cowan, R., Bezjak, A., Kirkbride, P., Parliament, M., Moynihan, C., Bahary, J-P., Parmar, M. K.B., Sanders, K., Bingshu, E. C., \& Mason, M. D., Impact of radiotherapy when added to androgen-deprivation therapy for locally advanced prostate cancer: long-term quality-of-life outcomes from the NCIC CTG PR3/MRC PRO7 randomized trial. Journal of Clinical Oncology, 2015. 33(19): p. 2151.

52. Warde, P., Mason, M., Ding, K., Kirkbride, P., Brundage, M., Cowan, R., Gospodarowicz, M., Sanders, K., Kostashuk, E., Swanson, G., Barber, J., Hiltz, A., Parmar, M. K.B., Sathya, J., Anderson, J., Hayter, C., Hetherington, J., Sydest, M. R., \& Parulekart, W, Combined androgen deprivation therapy and radiation therapy for locally advanced prostate cancer: a randomised, phase 3 trial. The Lancet, 2011. 378(9809): p. 2104-2111.

53. Sargos, P., Mottet, N., Bellera, C., \& Richaud, P., Long-term androgen deprivation, with or without radiotherapy, in locally-advanced prostate cancer: updated results from a phase III randomized trial. BJU international, 2019.

54. Daly, T., Evolution of definitive external beam radiation therapy in the treatment of prostate cancer. World journal of urology, 2019: p. 1-27.

55. Hatano, K., Tohyama, N., Kodama, T., Okabe, N., Sakai, M., \& Konoeda, K. , Current status of intensity-modulated radiation therapy for prostate cancer: History, clinical results and future directions. International Journal of Urology, 2019. 26(8): p. 775-784.

56. Tärnhuvud, M., Wändel, C., \& Willman, A., Nursing interventions to improve the health of men with prostate cancer undergoing radiotherapy: a review. European Journal of Oncology Nursing, 2007. 11(4): p. 328-339.

57. Paterson, C., Robertson, A., Smith, A., \& Nabi, G., Identifying the unmet supportive care needs of men living with and beyond prostate cancer: a systematic review. European Journal of Oncology Nursing, 2015. 19(4): p. 405-418.

58. Services, U.D.o.H.a.H. Common Terminology Criteria for Adverse Events (CTCAE) Version 5.0. 2017 [cited 2020 April 17]; Available from: 
https://ctep.cancer.gov/protocolDevelopment/electronic applications/docs/CTCAE v5 Quic $\underline{\text { k Reference } 5 \times 7 . p d f}$.

59. Primeau, C., Paterson, C., \& Nabi, G. A qualitative study exploring models of supportive care in men and their partners/caregivers affected by metastatic prostate cancer. in Oncology nursing forum. 2017. Oncology Nursing Society.

60. Paterson, C., \& Nabi, G., A model of consultation in prostate cancer care: Evidence from a systematic review. Cancer nursing, 2017. 40(4): p. 276-288.

61. Mottet N., B.J., Briers E., Bolla M., Bourke L., Cornford P., De Santis M., Henry A., Joniau S., Lam T., Mason M.D., Van den Poel H., Van den Kwast T.H., Rouvière O., Wiegel T. EAUESTRO-SIOG Guidelines on Prostate Cancer. 2020 [cited 2020 April 17]; Available from: https://uroweb.org/guideline/prostate-cancer/\#4.

62. Cox, J.D., Stetz, J., \& Pajak, T. F. Toxicity criteria of the radiation therapy oncology group (RTOG) and the European organization for research and treatment of cancer (EORTC). International Journal of Radiation Oncology• Biology• Physics 1995 [cited 31 5]; 1341-1346]. Available from: https://en.wikibooks.org/wiki/Radiation Oncology/Toxicity grading/RTOG. 
Figure 1: The process of reoxygenation [19]

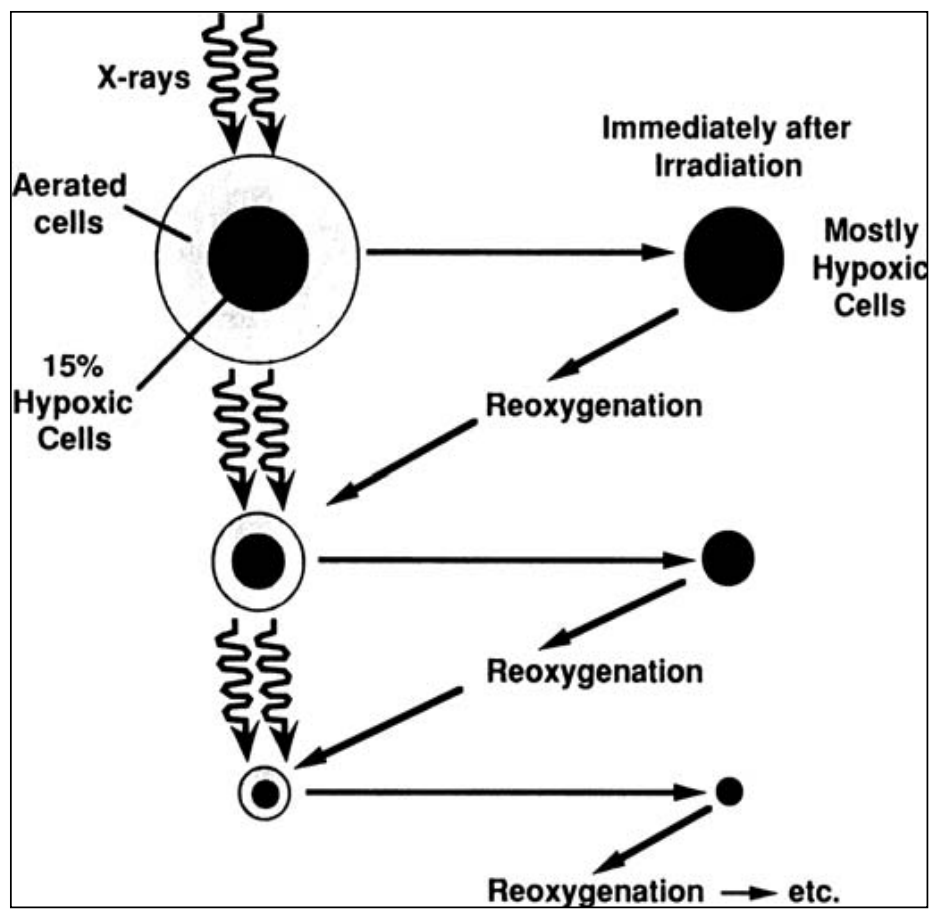

Figure 2: Four stages of the cell cycle [2].

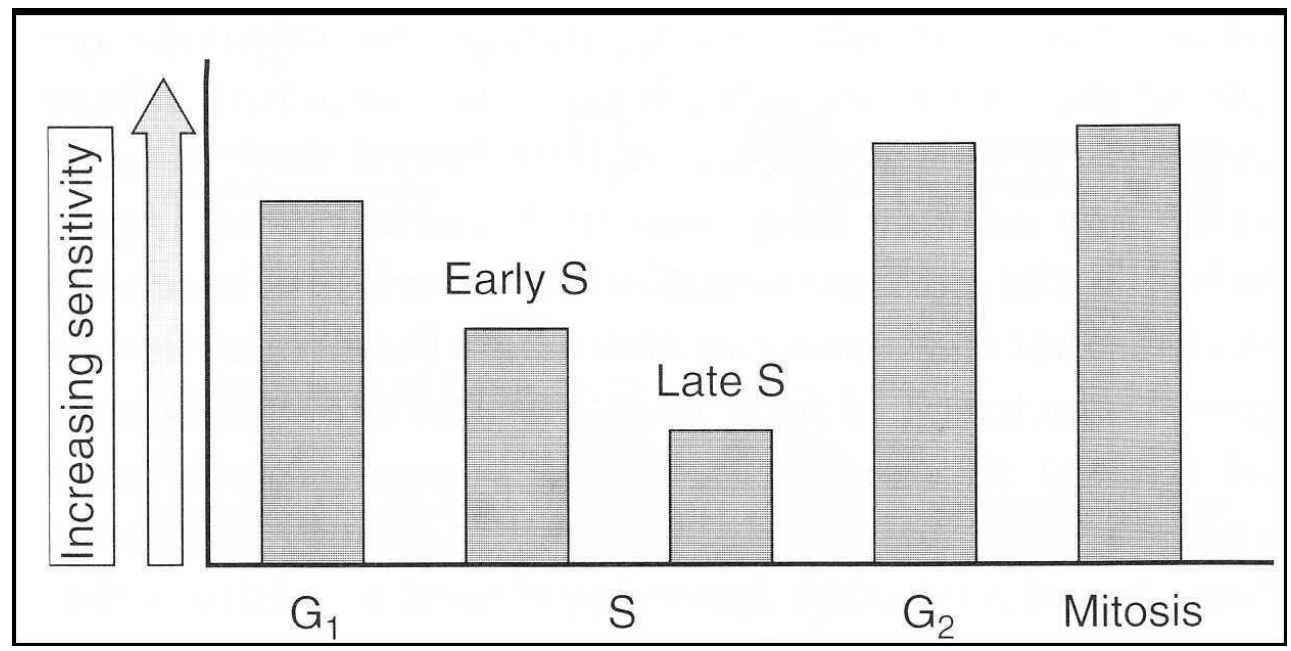


Table 1: Clinical Tumour Node Metastasis (TNM) classification of PCa [61]

\begin{tabular}{|c|c|c|}
\hline \multicolumn{3}{|c|}{ T - Primary Tumour (stage based on digital rectal examination [DRE] only) } \\
\hline TX & \multicolumn{2}{|c|}{ Primary tumour cannot be assessed } \\
\hline T0 & \multicolumn{2}{|c|}{ No evidence of primary tumour } \\
\hline \multirow[t]{4}{*}{ T1 } & \multicolumn{2}{|c|}{ Clinically inapparent tumour that is not palpable } \\
\hline & T1a & Tumour incidental histological finding in $5 \%$ or less of tissue resected \\
\hline & T1b & Tumour incidental histological finding in more than $5 \%$ of tissue resected \\
\hline & T1c & Tumour identified by needle biopsy (e.g. because of elevated prostate-specific antigen [PSA]) \\
\hline \multirow[t]{4}{*}{$\mathrm{T} 2$} & \multicolumn{2}{|c|}{ Tumour that is palpable and confined within the prostate } \\
\hline & $\mathrm{T} 2 \mathrm{a}$ & Tumour involves one half of one lobe or less \\
\hline & $\mathrm{T} 2 \mathrm{~b}$ & Tumour involves more than half of one lobe, but not both lobes \\
\hline & $\mathrm{T} 2 \mathrm{c}$ & Tumour involves both lobes \\
\hline \multirow[t]{3}{*}{ T3 } & \multicolumn{2}{|c|}{ Tumour extends through the prostatic capsule } \\
\hline & T3a & Extracapsular extension (unilateral or bilateral) \\
\hline & T3b & Tumour invades seminal vesicle(s) \\
\hline T4 & \multicolumn{2}{|r|}{$\begin{array}{l}\text { Tumour is fixed or invades adjacent structures other than seminal vesicles: external sphincter, rectum, } \\
\text { levator muscles, and/or pelvic wall }\end{array}$} \\
\hline \multicolumn{3}{|c|}{ N - Regional (pelvic) Lymph Nodes1 } \\
\hline NX & \multirow{2}{*}{\multicolumn{2}{|c|}{$\begin{array}{l}\text { Regional lymph nodes cannot be assessed } \\
\text { No regional lymph node metastasis }\end{array}$}} \\
\hline NO & & \\
\hline N1 & \multicolumn{2}{|c|}{ Regional lymph node metastasis } \\
\hline \multicolumn{3}{|c|}{ M - Distant Metastasis2 } \\
\hline Mo & \multicolumn{2}{|c|}{ No distant metastasis } \\
\hline M1 & \multicolumn{2}{|c|}{ Distant metastasis } \\
\hline & \multicolumn{2}{|c|}{ M1a Non-regional lymph node(s) } \\
\hline & \multicolumn{2}{|c|}{ M1b Bone(s) } \\
\hline & \multicolumn{2}{|c|}{ M1c Other site(s) } \\
\hline
\end{tabular}

${ }_{1}$ Metastasis no larger than $0.2 \mathrm{~cm}$ can be designated $\mathrm{pNmi}$.

2 When more than one site of metastasis is present, the most advanced category is used. ( $p) M 1 c$ is the most advanced category. 
Table 2: EAU risk groups for biochemical recurrence of localised and locally advanced prostate cancer [61]

\begin{tabular}{|l|l|l|l|}
\hline \multicolumn{1}{|c|}{ Low-risk } & \multicolumn{1}{|c|}{ Intermediate-risk } & \multicolumn{2}{c|}{ High-risk } \\
\hline PSA $<10 \mathrm{ng} / \mathrm{mL}$ & PSA $10-20 \mathrm{ng} / \mathrm{mL}$ & PSA $>20 \mathrm{ng} / \mathrm{mL}$ & any PSA \\
\hline and GS $<7$ (ISUP grade 1) & or GS 7 (ISUP grade 2/3) & or GS $>7$ (ISUP grade 4/5) & any GS (any ISUP grade) \\
\hline and cT1-2a & or cT2b & or cT2c & cT3-4 or cN+ \\
\hline \multicolumn{2}{|c|}{ Localised } & Locally advanced \\
\hline
\end{tabular}

GS = Gleason score; ISUP = International Society for Urological Pathology; PSA = prostate-specific antigen . 
Table 3a: RTOG ACUTE Radiation Morbidity [62]

\begin{tabular}{|c|c|c|c|c|}
\hline Tissue & Grade 1 & Grade 2 & Grade 3 & Grade 4 \\
\hline Lower GI / Pelvis & $\begin{array}{l}\text { Increased frequency or change } \\
\text { in quality of bowel habits not } \\
\text { requiring medication / rectal } \\
\text { discomfort not requiring } \\
\text { analgesics. }\end{array}$ & $\begin{array}{l}\text { Diarrhoea requiring } \\
\text { parasympatholytic drugs (e.g. } \\
\text { Lomotil) / mucous discharge not } \\
\text { necessitating sanitary pads / } \\
\text { rectal or abdominal pain } \\
\text { requiring analgesics. }\end{array}$ & $\begin{array}{l}\text { Diarrhoea requiring parenteral } \\
\text { support / severe mucous or } \\
\text { blood discharge necessitating } \\
\text { sanitary pads / abdominal } \\
\text { distention (flat plate radiograph } \\
\text { demonstrates distended bowel } \\
\text { loops). }\end{array}$ & $\begin{array}{l}\text { Diarrhoea requiring parenteral } \\
\text { support / severe mucous or } \\
\text { blood discharge necessitating } \\
\text { sanitary pads / abdominal } \\
\text { distention (flat plate radiograph } \\
\text { demonstrates distended bowel } \\
\text { loops). }\end{array}$ \\
\hline Genitourinary (GU) & $\begin{array}{l}\text { Frequency of urination or } \\
\text { nocturia twice pre-treatment } \\
\text { habit / dysuria, urgency not } \\
\text { requiring medication. }\end{array}$ & $\begin{array}{l}\text { Frequency of urination or } \\
\text { nocturia that is less frequent } \\
\text { than every hour. Dysuria, } \\
\text { urgency, bladder spasm } \\
\text { requiring local anaesthetic (e.g. } \\
\text { Pyridium). }\end{array}$ & $\begin{array}{l}\text { Frequency with urgency and } \\
\text { nocturia hourly or more } \\
\text { frequently / dysuria, pelvis pain } \\
\text { or bladder spasm requiring } \\
\text { regular, frequent narcotic / } \\
\text { gross haematuria } \\
\text { with/without clot passage. }\end{array}$ & $\begin{array}{l}\text { Haematuria requiring } \\
\text { transfusion / acute bladder } \\
\text { obstruction not secondary to } \\
\text { clot passage, ulceration, or } \\
\text { necrosis. }\end{array}$ \\
\hline
\end{tabular}

For all: 0 - no symptoms, 5 - death directly related to radiation effects 
Table 3b: RTOG/EORTC LATE Radiation Morbidity [62]

\begin{tabular}{|l|l|l|l|}
\hline \multicolumn{1}{|c|}{ Tissue } & \multicolumn{1}{|c|}{ Grade 1 } & \multicolumn{1}{c|}{ Grade 2 } & \multicolumn{1}{c|}{ Grade 3 } \\
\hline Small/Large Intestine & $\begin{array}{l}\text { Mild diarrhoea; mild cramping; } \\
\text { bowel movement 5 times daily; } \\
\text { slight rectal discharge or } \\
\text { bleeding. }\end{array}$ & $\begin{array}{l}\text { Moderate diarrhoea and colic; } \\
\text { bowel movement }>5 \text { times } \\
\text { daily; excessive rectal mucus or } \\
\text { intermittent bleeding. }\end{array}$ & $\begin{array}{l}\text { Obstruction or bleeding, } \\
\text { requiring surgery. }\end{array}$ \\
\hline Bladder & $\begin{array}{l}\text { Slight epithelial atrophy; minor } \\
\text { telangiectasia (microscopic } \\
\text { haematuria). }\end{array}$ & $\begin{array}{l}\text { Moderate frequency; } \\
\text { generalized telangiectasia; } \\
\text { intermittent macroscopic } \\
\text { haematuria. }\end{array}$ & $\begin{array}{l}\text { Severe frequency \& dysuria; } \\
\text { severe telangiectasia (often } \\
\text { with petechiae); frequent } \\
\text { haematuria; reduction in } \\
\text { bladder capacity (<150 cc). }\end{array}$ \\
\hline
\end{tabular}

For all: 0 - no symptoms, 5 - death directly related to radiation effects 